\title{
Portal Vein Thrombosis after Restorative Proctocolectomy for Familial Adenomatous Polyposis and Sigmoid Cancer
}

\author{
Abdul-Wahed Nasir Meshikhes Thabit Al-Ghazal \\ Department of Surgery, King Fahad Specialist Hospital, Dammam, Saudi Arabia
}

\section{Key Words}

Portal vein thrombosis - Familial adenomatous polyposis - Colon cancer - Restorative proctocolectomy

\begin{abstract}
Postoperative portal vein thrombosis (PVT) is rare, but has been described after various open as well as minimal access abdominal operations, especially splenectomy and colorectal surgical procedures. We report the case of a 39-year-old female who underwent restorative proctocolectomy and ileal pouch-anal anastomosis for familial adenomatous polyposis with sigmoid cancer. She presented 14 days later with vague upper abdominal pain, nausea, vomiting and high output stoma. Doppler ultrasonography confirmed PVT and therefore anticoagulant therapy was started. Her condition improved dramatically and she underwent closure of ileostomy after finishing adjuvant chemotherapy. She remained well at 3-year follow-up with good pouch function and no local or distant recurrence. A high index of suspicion is essential for early diagnosis and prompt treatment of postoperative PVT after restorative proctocolectomy. Early anticoagulation is essential to avoid subsequent complications.
\end{abstract}

\section{Introduction}

Familial adenomatous polyposis (FAP) is an inherited autosomal dominant syndrome. It is characterized by the development of multiple (hundreds to thousands) colorectal adenomatous polyps and if left untreated one or more of the adenomas will progress to colorectal cancer. Other gastrointestinal adenomas such as that of the stomach and duodenum may also occur. FAP may also be associated with other benign and malignant extracolonic manifestations such as desmoids tumors, epidermoid cysts, thyroid tumors, osteomas, hepatobiliary tumors, adrenocortical tumors, brain tumors

Dr. Abdul-Wahed Meshikhes, MB ChB, FRCS
Department of Surgery, King Fahad Specialist Hospital

Dammam 31444, Eastern Province (Saudi Arabia)

Tel. +96638431111 ext.6983, E-Mail meshikhes@gmail.com 
and congenital hypertrophy of the retinal pigment epithelium. The onset of FAP occurs at variable age ranges, but most commonly between the ages of 10 and 40 years. The best surgical treatment option for FAP is either total colectomy or restorative proctocolectomy (RP) and ileal pouch-anal anastomosis (IPAA) with a defunctioning ileostomy [1-3]. The former procedure is performed if the rectum is spared of polyps, but the latter (RP and IPAA) when the rectum is also involved in the polyposis process. The stoma is usually closed 3 months later after confirming the integrity of the ileal pouch by radiological and/or endoscopic investigations. The procedure is a major surgical undertaking and is associated with considerable morbidity. The most common complications of RP are dysplasia and pouch-related problems such as pouch leakage, pouch sinus or fistula, and pouchitis. Other complications include pelvic abscess, small bowel obstruction, anastomotic stricture, postoperative bleeding, fecal incontinence, and sexual dysfunction [1-3].

Portal vein thrombosis (PVT) has been reported as one of the postoperative complications that occur after certain open as well as laparoscopic abdominal surgical procedures. It is most commonly described after splenectomy, especially those performed for hematological diseases [4]. It may occur to a lesser extent after colorectal procedures, especially those for ulcerative colitis such as RP and IPAA [5-7]. PVT presents as a clinical spectrum of abdominal pain, fever, and leukocytosis. Anticoagulation treatment is usually associated with resolution of symptoms.

We report a case of PVT presenting 7 days after discharge from hospital following RP and IPAA for FAP with sigmoid cancer to highlight this uncommon but serious postoperative complication.

\section{Case Report}

A 39-year-old female was referred with a 2-month history of rectal bleeding and altered bowel habits in the form of increasing constipation. She denied any family history of polyposis or colorectal cancer. Clinical examination revealed no pallor, jaundice or lymphadenopathy, and the abdomen was soft and lax with a lower midline scar of a previous hysterectomy which had been performed 20 years before. There were no palpable masses or organomegaly and rectal examination was normal. Routine blood tests including complete blood count, and renal and liver panels were all normal. The coagulation profile (PT: $12 \mathrm{~s}$ [normal range 10-14]; INR: $1.1 \mathrm{~s}$ [normal range 0.8-1.2]) and carcinoembryonic antigen $(1.88 \mu \mathrm{g} / \mathrm{l}$ [normal range $0-5]$ ]) were also normal. A computed tomography (CT) scan with intravenous and rectal contrasts showed a mass in the sigmoid colon with typical

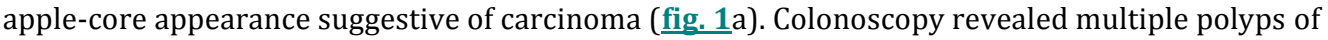
variable sizes in the colon consistent with FAP (fig. 1b), and a circumferential malignant stricture was noted $28 \mathrm{~cm}$ from the anal verge. Biopsies confirmed moderately differentiated adenocarcinoma. The patient underwent elective RP and IPAA ( fig. 2) with a diverting ileostomy. The procedure was uneventful and the histopathology report showed invasive well-differentiated adenocarcinoma; 4 out of 91 lymph nodes were positive for malignancy (stage T3, N2, M0). She was discharged 1 week after the procedure with a plan for postoperative adjuvant chemotherapy, family screening and closure of ileostomy after the completion of chemotherapy. However, 7 days after discharge she felt unwell with vague colicky upper abdominal pain, nausea, occasional vomiting, and high output stoma, but no fever. Abdominal ultrasonography and Doppler scan (fig. 3 ) showed PVT for which she was treated with anticoagulant therapy. One month later she received neoadjuvant chemotherapy in the form of 4 cycles of XELODA which was shifted later to 3 cycles of FOLFOX. Repeat abdominal ultrasonography showed recanalization of the thrombus and formation of collaterals. After completion of the chemotherapy cycles, the ileostomy was closed after the pouch integrity was confirmed. Her postoperative course was uneventful and she remained well at 36-month follow-up. 


\section{Discussion}

PVT has been reported after certain surgical procedures such as splenectomy, cholecystectomy, laparoscopic appendicectomy, liver transplantation, and intraabdominal sepsis following appendicitis, diverticulitis, chronic and acute pancreatitis, liver abscess and cholangitis [8-15]. Its presentation is variable and depends on whether the thrombosis is acute or chronic. Acute PVT presents with symptoms of intestinal congestion and ischemia such as abdominal pain, distension, diarrhea, rectal bleeding, anorexia, fever, leukocytosis, lactic acidosis and sepsis [15]. Chronic PVT is however asymptomatic due to development of collaterals and is characterized by splenomegaly, pancytopenia, varices and possibly ascites [15].

To establish an early diagnosis, a high index of suspicion should be exercised in any patient presenting with vague abdominal pain, nausea, fever and leukocytosis following recent abdominal surgery, especially after splenectomy and colorectal procedures, and in those with intraabdominal sepsis. Ultrasonography is the investigation of choice and Doppler imaging helps to establish the presence or absence of flow in the vessel lumen [16]. CT scan may help to detect the underlying cause and magnetic resonance angiography helps to identify the direction of the flow, patency of the portal system and presence of varices [17].

The management is usually aimed at reducing the associated morbidity and mortality by reversal or prevention of progression of the thrombosis and also at treating complications of PVT [15]. The debate over whether to offer thrombolysis or systemic anticoagulation remains unresolved due to lack randomized control data. However, there is clear evidence that early medical intervention is beneficial [18]. In a retrospective study of 33 cases of acute PVT (symptoms occurred 8-60 days prior to presentation), conservative treatment in 5 patients proved to be fatal. However, fibrinolytic treatment resulted in rapid general improvement and recanalization in 10 patients in whom disease history was $<14$ days and in partial portal vein occlusion with restoration of hepatopedal flow with normal liver function in another 13 patients in whom disease history was slightly longer than 14 days [18]. The treatment failed in another 5 patients with a history of PVT longer than 30-40 days [18]. Condat et al. [19] retrospectively reviewed patients with acute PVT but with no evidence of portal hypertension. Recanalization occurred in 25 out of 27 patients $(92.6 \%)$ who received anticoagulation therapy. Two patients received no anticoagulation and hence no recanalization occurred. It was therefore advocated that early anticoagulation is beneficial in acute PVT and results in recanalization [19].

A collective review of the literature for PVT following RP revealed three retrospective studies (table 1). In a retrospective study by Millan et al. [5] of patients undergoing RP from 1997 to 2000, 37 patients (21.76\%) with confirmed PVT were matched with 133 patients without. Both groups were compared with respect to pouch function and quality of life. It was concluded that although PVT can be a serious complication after restorative proctocolectomy, it usually resolves with timely and appropriate anticoagulation. More importantly, long-term pouch function and quality of life are not affected by this complication [5]. Ball et al. reviewed 112 patients who underwent IPAA for ulcerative colitis and assessed the rate of PVT [6]. 45.5\% of patients with PVT suffered pouchitis versus $15.4 \%$ patients without PVT who had pouchitis. It was concluded that PVT is a common finding in patients who require a CT 
scan examination after IPAA. Moreover, patients who suffer PVT have a higher incidence of postoperative pouchitis [6]. However, it is not clear whether the pouchitis predisposed to PVT as any other intraabdominal sepsis or PVT was the triggering factor for development of pouchitis [6, 7]. Remzi et al. [7] reviewed 94 ulcerative colitis patients who had CT scans performed in the postoperative period after RP for symptoms such as abdominal pain, fever, leukocytosis or delayed bowel function. PVT was diagnosed in 42 patients (45\%), 22 patients had PVT without sepsis. Sepsis was present in 45 patients, 20 of whom had PVT. It was concluded that PVT may be subtle enough to go undiagnosed without serious consequences, even when not treated. Also, patients treated with anticoagulation recover completely [7]. It is worth noting that the experience of Remzi et al. [7] and that of Millan et al. [5] are from the same institution and may harbor duplicate data.

Our case highlights that PVT presents with vague upper gastrointestinal symptoms and can occur 10-14 days after RP or any abdominal operation (open or laparoscopic). A high index of suspicion is essential for early diagnosis and prompt treatment of this condition with anticoagulation to avoid subsequent pouchitis.

Table 1. Published studies of PVT after restorative proctocolectomy

\begin{tabular}{|c|c|c|c|}
\hline Reference & Study type & $\begin{array}{l}\text { Number of patients and } \\
\text { findings }\end{array}$ & Remarks \\
\hline $\begin{array}{l}\text { Millan et al. [5], } \\
2007\end{array}$ & $\begin{array}{l}\text { Retrospective case-control } \\
\text { study. All patients } \\
\text { underwent RP ( } 62.4 \% \text { had } \\
\text { ulcerative colitis). }\end{array}$ & $\begin{array}{l}37 \text { with vs. } 133 \text { without PVT } \\
(21.7 \%) .45 .5 \% \text { of patients with } \\
\text { PVT suffered pouchitis vs. } \\
15.4 \% \text { patients without PVT. }\end{array}$ & $\begin{array}{l}\text { PVT is a serious complication and a common finding in } \\
\text { patients who require a CT scan examination after RP. } \\
\text { Patients with PVT have a higher incidence of } \\
\text { postoperative pouchitis. No significant differences with } \\
\text { respect to long-term pouch function, episodes of } \\
\text { pouchitis, or quality of life between the two groups. }\end{array}$ \\
\hline $\begin{array}{l}\text { Ball et al. [6], } \\
2007\end{array}$ & $\begin{array}{l}\text { Retrospective review of CT } \\
\text { scans of ulcerative colitis } \\
\text { patients who underwent } \\
\text { CT scanning in the } \\
\text { postoperative period after } \\
\text { IPAA for symptoms. }\end{array}$ & $\begin{array}{l}28 / 72(39 \%) \text {. CT scan was } \\
\text { positive for PVT in } 39 \% \text { of } \\
\text { patients with symptoms. }\end{array}$ & $\begin{array}{l}\text { PVT is common in the subset of patients who require CT } \\
\text { scan for postoperative symptoms after IPAA. Patients } \\
\text { who suffer PVT have a higher incidence of postoperative } \\
\text { pouchitis. }\end{array}$ \\
\hline $\begin{array}{l}\text { Remzi et al. [7], } \\
2002\end{array}$ & $\begin{array}{l}\text { Retrospective study. } \\
94 \text { patients has CT scan in } \\
\text { the postoperative period. }\end{array}$ & $\begin{array}{l}\text { PVT was diagnosed in } 42 \\
\text { patients }(45 \%) .22 \text { patients } \\
(23 \%) \text { had PVT without sepsis. } \\
45(47.8 \%) \text { had sepsis, } 20 \text { of } \\
\text { them had PVT. }\end{array}$ & $\begin{array}{l}\text { PVT can be found in a high proportion of patients } \\
\text { undergoing abdominal CT scan after RP. It may be subtle } \\
\text { enough to go undiagnosed and to have no serious } \\
\text { consequences, even when not treated. Patients treated } \\
\text { with anticoagulation recover completely. }\end{array}$ \\
\hline
\end{tabular}




\begin{tabular}{r|l|l|l}
$\begin{array}{r}\text { Case Reports in } \\
\text { Gastroenterology }\end{array}$ & $\begin{array}{l}\text { Case Rep Gastroenterol 2012;6:124-130 } \\
\text { DOI: 10.1159/000337147 }\end{array}$ & $\begin{array}{l}\text { Published online: } \\
\text { February 24, 2012 }\end{array}$ & $\begin{array}{l}\text { @ 2012 S. Karger AG, Basel } \\
\text { ISSN 1662-0631 } \\
\text { www.karger.com/crg }\end{array}$ \\
\hline
\end{tabular}
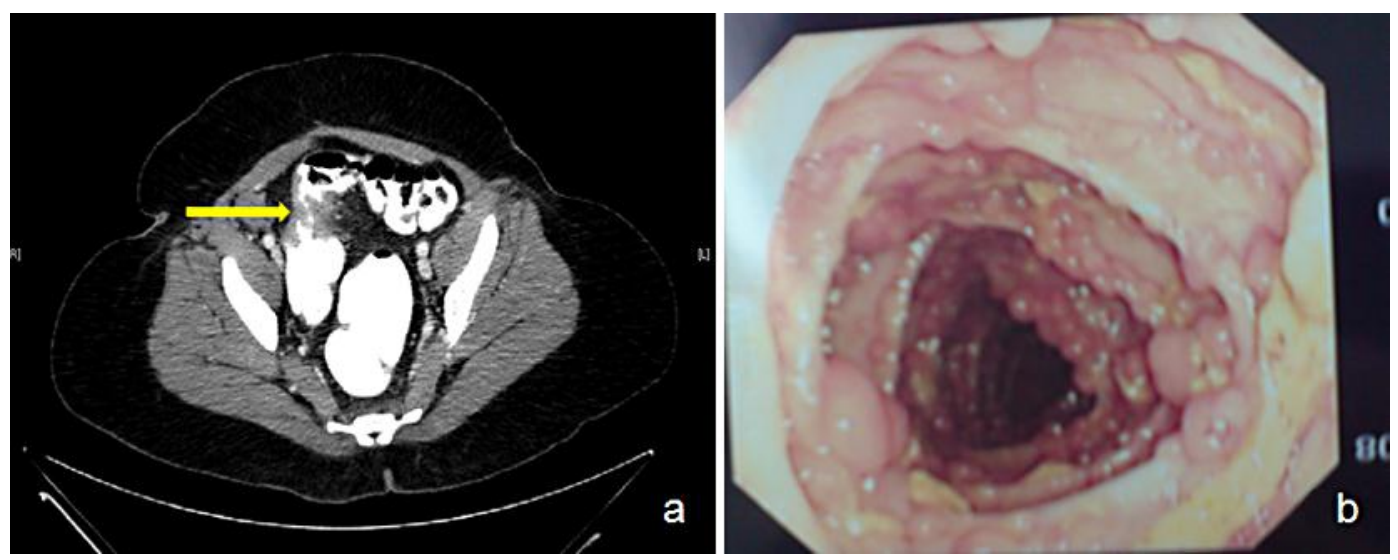

Fig. 1. a CT scan with rectal contrast showing the malignant lesion with apple-core appearance in the sigmoid colon (arrow). b Colonoscopic view of the colon showing numerous polyps of variable sizes.

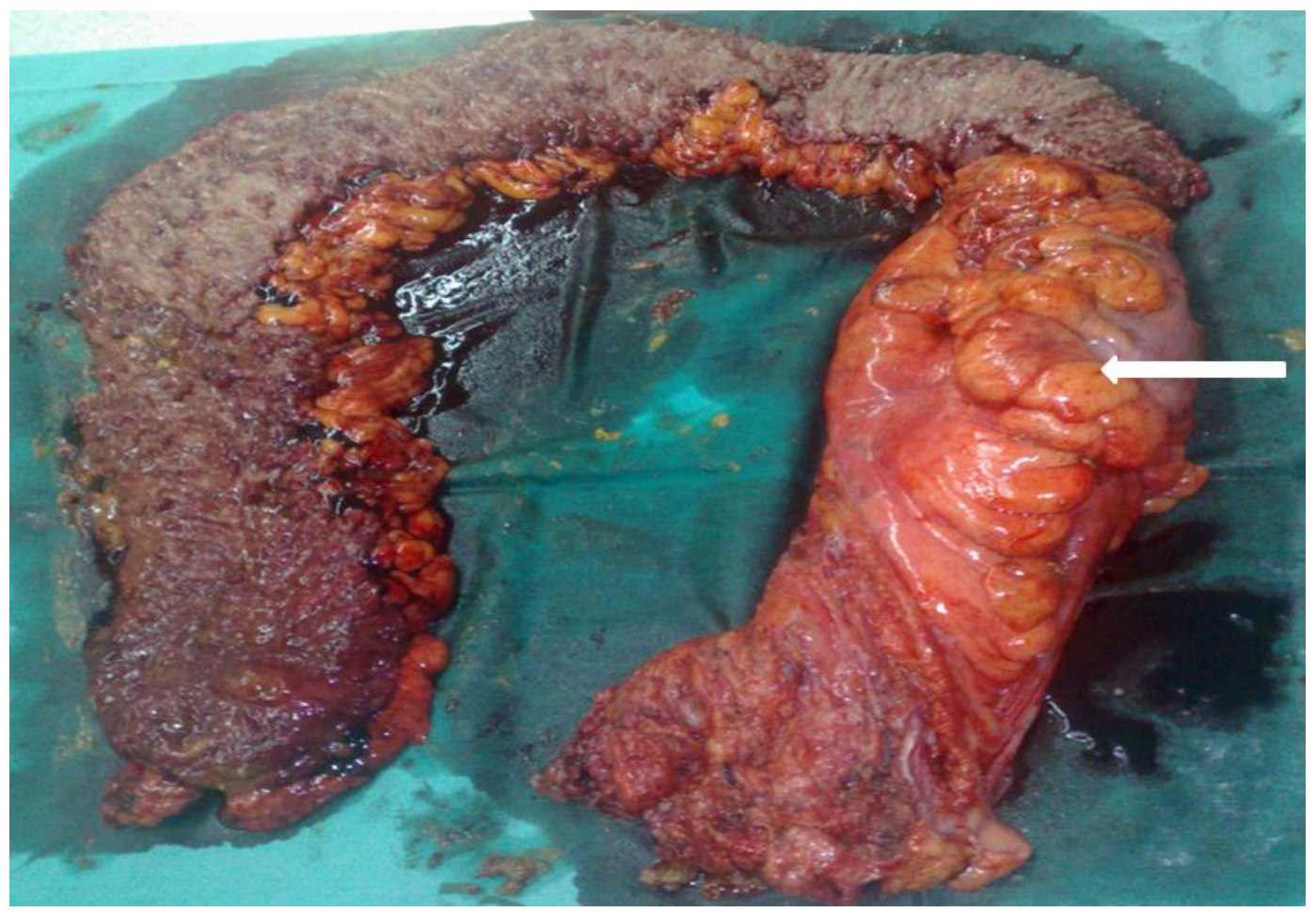

Fig. 2. Operative specimen showing multiple polyps throughout the colon. The cancer-bearing sigmoid colon (arrow) was left intact for proper histological staging. 


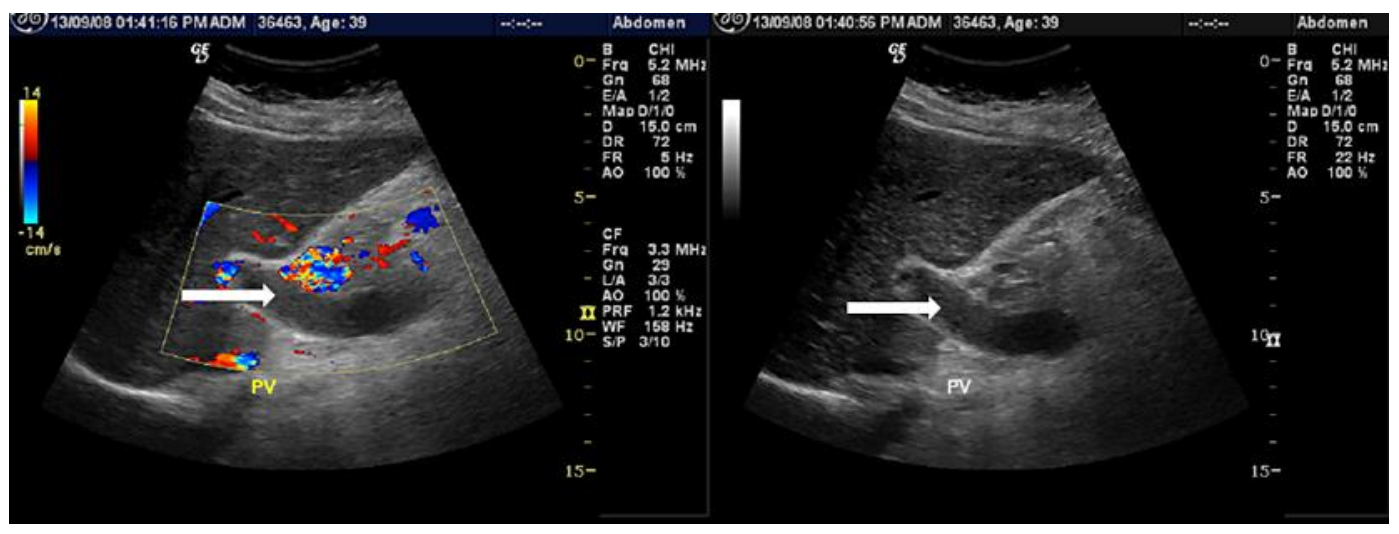

Fig. 3. Doppler ultrasonography showing the portal vein with a thrombus (arrows).

\section{References}

1 Fazio VW, Ziv Y, Church JM, Oakley JR, Lavery IC, Milsom JW, Schroeder TK: Ileal pouch-anal anastomoses complications and function in 1,005 patients. Ann Surg 1995;222:120-127.

2 Fazio VW, Tekkis PP, Remzi F, Lavery IC, Manilich E, Connor J, Preen M, Delaney CP: Quantification of risk for pouch failure after ileal pouch anal anastomosis surgery. Ann Surg 2003;238:605-614.

-3 Keighley MR, Grobler S, Bain I: An audit of restorative proctocolectomy. Gut 1993;34:680-684.

-4 Winslow ER, Brunt LM, Drebin JA, Soper NJ, Klingensmith ME: Portal vein thrombosis after splenectomy. Am J Surg 2002;184:631-635.

5 Millan M, Hull TL, Hammel J, Remzi F: Portal vein thrombi after restorative proctocolectomy: serious complication without long-term sequelae. Dis Colon Rectum 2007;50:1540-1544.

6 Ball CG, MacLean AR, Buie WD, Smith DF, Raber EL: Portal vein thrombi after ileal pouch-anal anastomosis: its incidence and association with pouchitis. Surg Today 2007;37:552-557.

-7 Remzi FH, Fazio VW, Oncel M, Baker ME, Church JM, Ooi BS, Connor JT, Preen M, Einstein D: Portal vein thrombi after restorative proctocolectomy. Surgery 2002;132:655-661.

-8 Mangia A, Villani MR, Cappucci G, Santoro R, Ricciardi R, Facciorusso D, Leandro G, Caruso N, Andriulli A: Causes of portal venous thrombosis in cirrhotic patients: the role of genetic and acquired factors. Eur J Gastroenterol Hepatol 2005;17:745-751.

-9 Vecchio R, Cacciola E, Cacciola RR, Marchese S, Intagliata E: Portal vein thrombosis after laparoscopic and open splenectomy. J Laparoendosc Adv Surg Tech A 2011;21:71-75.

10 Ayantunde AA, Debrah SA: Portal vein thrombosis complicating appendicitis. West Afr J Med 2004;23: 332-334.

11 Egawa H, Tanaka K, Kasahara M, Takada Y, Oike F, Ogawa K, Sakamoto S, Kozaki K, Taira K, Ito T: Single center experience of 39 patients with preoperative portal vein thrombosis among 404 adult living donor liver transplantations. Liver Transpl 2006;12:1512-1518.

12 Vadalà S, Cinardi N, Li Volti G, Foresta G, Giannone G: Portal vein thrombosis following laparoscopic total mesorectal excision: case report. Tech Coloproctol 2008;12:259-261.

-13 Lladó L, Fabregat J, Castellote J, Ramos E, Torras J, Jorba R, Garcia-Borobia F, Busquets J, Figueras J, Rafecas A: Management of portal vein thrombosis in liver transplantation: influence on morbidity and mortality. Clin Transplant 2007;21:716-721.

14 Targarona EM: Portal vein thrombosis after laparoscopic splenectomy: the size of the risk. Surg Innov 2008;15:266-270.

15 Wang JT, Zhao HY, Liu YL: Portal vein thrombosis. Hepatobiliary Pancreat Dis Int 2005;4:515-518.

16 Chawla Y, Duseja A, Dhiman RK: Review article: the modern management of portal vein thrombosis. Aliment Pharmacol Ther 2009;30:881-894. 
17 Ito K, Siegelman ES, Stolpen AH, Mitchell DG: MR imaging of complications after liver transplantation. AJR Am J Roentgenol 2000;175:1145-1149.

18 Malkowski P, Pawlak J, Michalowicz B, Szczerban J, Wroblewski T, Leowska E, Krawczyk M: Thrombolytic treatment of portal thrombosis. Hepatogastroenterology 2003;50:2098-2100.

19 Condat B, Pessione F, Helene Denninger M, Hillaire S, Valla D: Recent portal or mesenteric venous thrombosis: increased recognition and frequent recanalization on anticoagulant therapy. Hepatology 2000;32:466-470. 